\title{
The Big Role of Authority, Sanctity, and Modern Myths About Sexual Aggression in Blaming the Rape Victims: A Study on Culture of Honor
}

\author{
Mazyar Bagherian Miandoab', Zohreh Hashemi Dezaki ${ }^{* 2}$, Bahare Bahmani
}

\author{
${ }^{1}$ Department of Psychology, Faculty of Education and Psychology, University of Tabriz, Tabriz, Iran. \\ 2 Department of Psychology, Faculty of Humanities, University of Maragheh, Maragheh, Iran.
}

\begin{abstract}
According to Moral Foundation Theory, people rely on five intuitive-based foundations in their moral judgments. These foundations are divided into two clusters: Individualizing foundations (Care and Fairness) and Binding foundations (Loyalty, Authority, and Sanctity). In this study, the authors investigated the relationship between moral foundations and AMMSA with victim-blaming and the moderating role of social desirability in Iranian Culture. Consistent with previous findings, victim-blaming was best predicted by AMMSA. Regarding moral foundations, victim-blaming was positively predicted by Authority and Sanctity and negatively predicted by Fairness. Although the best predictor of victim-blaming was AMMSA, Authority and Sanctity had a marginal difference with AMMSA in predicting victim-blaming. Analyses also showed that higher levels of Social Desirability moderated the Care foundation. Moreover, while there was no difference in victim-blaming among men and women, men were more accepting of AMMSA. With attention to previous literature, findings are discussed to gain a better understanding of the interaction between moral foundations and victim-blaming in various cultural contexts.
\end{abstract}

Key words: Victim-blaming, Acceptance of Modern myths about sexual aggression, Moral foundations, Iran, Rape

\section{Introduction}

Sexual aggression and rape are among the most pervasive social problems of today's modern age. Although in the last few decades, existing viewpoints toward rape and rape victims have changed drastically, and after social movements such as \#Me_too women started to report their experiences of rape, it is still a type of crime that remains unspoken and unreported. United Nations and World Health Organization's statistics estimate that almost 736 million women worldwide (approximately 1 in 3) at least one-time experience partner sexual violence, non-partner sexual violence, or both during some stage in their life (WHO, 2021). Rape is a phenomenon that exists internationally and has no cultural boundaries or exceptions among different countries (Grubb \& Turner, 2012). However, some developments have taken place regarding rape and sexual aggression reports in the last years. For instance, HOSP has reported that 4.2\% of women experience rape, and almost 20\% of them are reporting that they have suffered some sort of sexual victimization in their life (HOSB, 2009). Nevertheless, these signs of progress generally belong to industrial countries. In developing countries, specifically middle eastern countries where cultures of honor are hugely prominent, rape victims are still tending not to report their experiences and remain silent (Bastani, 2017).

${ }^{*}$ Corresponding author: Department of Psychology, Faculty of Humanities, University of Maragheh, Daneshgah Boulevard, Maragheh, East Azarbaijan, Iran. Email: z.hashemi@maragheh.ac.ir 
As mentioned above, in developing countries, rape victims are generally reluctant to report their experience because it can put them in a "secondary victimization" situation (Burt, 1980; Campbell et al., 1999; Winkel \& Koppelaar, 1991). In the literature, secondary victimization has been chiefly used for rape victims (Campbell, 2008). It is a term that applies for describing the harms and adverse reactions that victims of traumatic incidents receive from either official (i.e., judicial systems, police, or health care organizations) or unofficial resources (i.e., family, friends, or society) (Brown, 2007; Laing, 2017). In these situations, victims are doubted, blamed, treated as responsible for their experience, and the psychological impact of the assault on them are minimized. Thus, victims not only have to cope with psychological pressures and harms that are caused to them, but they also have to withstand negative behaviors and treatments from surroundings and official organizations. As Campbell (2008) puts it, seeking help after trauma becomes a "second rape" for victims. However, in addition to these outcomes, in some middle eastern cultures, reporting and seeking help may result in convictions of adultery by the judicial system and honor killings of rape victims.

One major factor contributing to victim-blaming is the endorsement of rape myths (Brownmiller, 1975; Mason et al., 2004). Rape myths are "wrong," descriptive, and prescriptive beliefs that justify rape and exonerate the perpetrator; are held extensively and consistently, and their object is sustaining men's aggression on women and abiding the blaming of the victim (Bohner et al., 1998; Burt, 1980; Lonsway \& Fitzgerald, 1994). Rape myths acceptance (RMA) creates a hostile environment in a given society that rape victims are blamed instead of rapists. Researchers have found high levels of relationship between RMA and the variables related to sexism and negative attitudes toward women. For instance, studies in Lebanon and Pakistan showed hostile and benevolent sexism (Glick \& Fiske, 2001) are positively correlated with RMA, and in both studies, the levels of RMA were higher in men than women (Nisar, 2021; Sanchez-Ruiz et al., 2021). People who have higher scores in RMA scales tend to think that rape is not a severe problem for victims and often do not suggest reporting the incident to the police (Frese et al., 2004; Krahé, 1988). On the other hand, endorsement of rape myths has an anxiety-buffering role for women. Women with higher RMA scores tend to believe that rape is not a potential threat for them and is more likely to happen among women whose behaviors are deemed inappropriate (for example, wearing short skirts) and attention-seeking (Bohner et al., 2013).

Consistent with sexism and racism, and along with the rise of feminist movements and social changes in recent decades, belief in sexual myths has taken on more implicit forms and is not explicitly expressed (Gerger et al., 2007; Milesi et al., 2020; Swim et al., 1995); and therefore, due to desirability concerns, measuring these beliefs with traditional scales is more difficult in the modern age (Megías et al., 2011). For example, different researchers in many cultures used these scales and discovered that most participant's responses had a positive skewness (Bohner et al., 1999; Bohner et al., 2006; Frese et al., 2004; Payne et al., 1999). In order to address this issue, researchers have developed new scales for assessing RMA. The Acceptance of Modern Beliefs About Sexual Aggression (AMMSA) (Gerger et al., 2007), used in this study, has been designed based on recent developments in modern sexism and uses more subtle expressions to measure people's judgments about rape victims.

Blaming the rape victim is a matter of moral judgment. Kohlberg and Herch (1977) proposed a model of moral development in which RMA is related to lower levels of moral development (Kohlberg \& Hersh, 1977; Wilson et al., 2002). On the other hand, Bandura (1968) indicated that mechanisms of moral disengagement are embodied in rape myths which are likely to result in blaming the rape victims and exonerate the rapist (Bandura, 1986; Page \& Pina, 2018). One of the most comprehensive theories that attempt to address the roots of people's moral judgments is Moral Foundations Theory (Graham et al., 2013; Haidt, 2012). Moral foundations theory is based on four core assumptions: (1) morality is the result of evolutionary processes- it is an "inner experience" or "organizes in advance to experience (Graham et al., 2013);" (2) morality is strongly 
influenced by culture and learning; (3) the third assumption is that moral decision making is usually fast, intuitive, and affect-laden- meaning that moral judgments come first, then arguments are proposed. People usually have no awareness of the mechanisms that shape their judgments, but there are aware of their consequences and can realize whether their judgments were morally wrong or right (Haidt, 2001); (4) there are at least five domains that people rely on them in their judgments.

These five domains are Care/Harm, Fairness/Cheating, Loyalty/Betrayal, Authority/Subversion, Sanctity/Degradation. Care foundation refers to intrinsic tendencies to protect others and prevent harm from them. Although individuals with higher scores in this foundation are more sensitive to signs of distress and suffering of others and show more sympathy and compassion; as it can be predicted, lack of endorsement of this foundation has a positive relationship with RMA and blaming the rape victims (Milesi et al., 2020; Watts et al., 2017). Fairness is sensitive to issues related to rights, equity, and justice. Studies have shown that endorsement of this foundation is negatively correlated with hostile sexism (Vecina \& Piñuela, 2017), and hostile sexism and fairness foundations positively associate with blaming the rape victim (Graham et al., 2009; Milesi et al., 2020). Care and Fairness foundations are called Individuating values. Individuating values are strongly consistent with the term "dyadic morality" (Gray et al., 2012; Schein et al., 2015) - which argues that people usually have this view that immoral incidents are situations in which an agent (perpetrator in the case of rape) harms the victim (rape victim). Thus, it can be argued that people with high endorsements of individualizing values are less likely to blame the rape victims (Niemi \& Young, 2016).

The other three foundations- Loyalty, Authority, Sanctity- are called binding foundations. Higher scores in binding foundations are positively correlated with the increased evaluations that victims are contaminated, attributions of blame and holding the victim as responsible, and less focusing on perpetrators (Niemi \& Young, 2016). Loyalty foundation refers to the values of bonding with tribe, family, and community. Harper and Harris (2017) theoretically argued that loyalty might be related to the tendency to perceive sexual offenders and rapists in terms of "stranger danger" heuristic, which disregards that the vast majority of Sexual offenses takes place among trusted community members or people that are not perceived as "strangers" (e.g., colleague) (Harper \& Harris, 2017). Authority foundation refers to the value of respect to law and social hierarchies. This value is associated with traditional gender roles and ambivalent sexism, which are associated with blaming the rape victims (Abrams et al., 2003; Baboli \& Karimi-Malekabadi, 2020; Vecina \& Piñuela, 2017). Harper \& Harris (2017) argued that endorsement of this value might predict less punitive opinions toward the acquaintance perpetrators and sexual aggression in families (Harper \& Harris, 2017). Finally, the Sanctity foundation is closely related to disgust and involves preserving physical and spiritual purity. Authority and Sanctity foundations positively predict blaming the rape victim, but Sanctity does this in interaction with AMMSA (Milesi et al., 2020).

\section{2. Morality, AMMSA, and Victim Blaming in Iran}

With over 82 million (1\% of the world's population), and rich ancient history, Iran is one of the countries where the problem of victim-blaming and AMMSA have not been studied yet (Baboli \& Karimi-Malekabadi, 2020). Despite previous studies in industrialized and WIERD countries, this field's literature in developing, non-WEIRD countries are lacking and inadequate. Studies showed that Iran is neither a WIERD nor a non-WIERD country; instead, it is more of a "WEIRD" non-WIERD country (Atari et al., 2020). For example, although Iran is historically, culturally, and religiously similar to the other Middle East and North Africa countries, it is more developed and has a higher education level (UN, 2018). This issue makes Iran a specific place because it seems that Iran does not fall into any of the classifications of WIERD or non-WIERD countries. Therefore, the findings obtained about the cultures belonging to these two categories cannot be attributed to Iran. 
In addition to the secondary victimization that rape victims face in other countries and cultures, In Iran, People who are raped and sexually abused have to deal with some problems specific to Iranian culture. These dilemmas cause many victims not to seek help or delay in seeking. For example, there are no official statistics on the rate and the incidents of rapes in Iran, which can be a sign of lack of support and attention to rape victims (Aghtaie, 2017; Shahali et al., 2016). In addition, cultural-specific values such as Qeirat, Haya, and Namous play essential role in Iranian society, and individuals emphasize on these concepts in their moral decisions (Atari et al., 2020; Baboli \& Karimi-Malekabadi, 2020). Qeirat is a culture-specific term that cannot be accurately translated into English (but the closest equivalent is probably "Honor") and is usually used to describe a range of emotions that are triggered in response to threats to Namous (Razavi et al., 2020). Namous refers to female members of a family as a symbol of honor that men must protect (FIS, 2015). To sum up, Gheirat is a cultural-specific moral value that involves protecting female kins and romantic partners (and on a larger scale country and ideals) (Atari et al., 2020; Tabatabai, 1996). Although this concept is more common among men and can be considered a masculine concept, it seems that Iranian women consider Gheirat as a sign of attractiveness in mate selection and mate retention (Atari \& Jamali, 2016). Therefore, based on these findings, we argue that there will be no difference between men and women in their endorsement of Gheirat. Research shows that people with high levels of Gheirat endorsement are more likely to blame rape victims (Baboli \& Karimi-Malekabadi, 2020).

One commonality among countries with Honor Cultures is that they try to maintain their current status by protecting their reputation and avoiding violating society's norms (Razavi et al., 2020). In Iran, as a culture of honor, the word Aberoo is used for this concept. Therefore, victims of rape and their families are less likely to report such crimes due to of fears of losing their status and preserving their reputation (Aghtaie, 2011). In some cases, due to fear of being honored-killed by their own family, rape victims may not tell their experiences to close family (e.g., parents and siblings) (Onsi, 2017). It can be argued that the roots of such beliefs are in sexual myths that are accepted by society. Farajiha and Azari (2011) argued that failure in reporting rape crimes can be due to the prevalence of rape myths in the judiciary and culture, in which rape victims are often considered accomplices; therefore, this belief forms that they must have done something wrong which had this consequence. For example, judges in their judgments of rape often emphasize that there is no reason for a woman to go to a stranger man's house (anyone except father, brother, husband), and therefore, if a woman is raped, she is partly responsible for this outcome (Kar, 2015).

The roots and reasons of such judgments can be traced within moral psychology. However, as mentioned before, unlike the WEIRD countries, the subjects of moral psychology and moral judgments in Iran have not been studied extensively. As far as we know, except for a small number of studies on moral psychology in Iran (Atari et al., 2020; Baboli \& Karimi-Malekabadi, 2020; Nejat et al., 2015, 2016), other studies in this field have been mainly based on observation, religious teachings, and lacking empirical studies (Jamalzadeh, 1966; Tabatabai, 1996). Currently, the Most recent studies are at the beginning of forming culture-specific models for the moral judgments of Iranian culture (Atari et al., 2020). The Theory of Moral Foundations (Graham et al., 2013; Haidt, 2012) investigates the foundations of individuals' moral judgments in the five foundations mentioned earlier. Very few studies have examined the relationship between the Moral Foundation, AMMSA, and victim-blaming in Iran. For example, in their analysis of Iranian samples, Baboli and Karimi-Malekabadi (2020) found that high authority values and low care predict the blaming of rape victims. They also found that endorsement of Gheirat value had the highest relationship with victim-blaming. Atari et al. (2020), in their broad study of Moral Foundations on Iranian culture, found that Gheirat is a cultural-specific value that Iranians believe in beyond the five moral foundations, and this value is highly correlated with Binding Foundations. They also found that the network connections of foundations in Iran were different from those seen in the United States and other WEIRD countries. Therefore, according to these two studies (Atari et al., 
2020; Baboli \& Karimi-Malekabadi, 2020) we can expect binding moral foundations to be correlated with blaming the rape victims in Iranian culture.

\section{The Present Study}

In this study, based on Milesi et al. (2020), we examined the relationship between moral foundations and AMMSA with victim-blaming in Iranian culture. Megías et al. (2011) suggested that traditional RMA scales are vulnerable to social desirability tendencies and AMMSA questionnaire was designed as a solution for this problem. However, Considering the Iran-specific "me-too" movements that happened during 2020-21 in which women started to share their experiences of sexual harassment on social media (Sepehri Far, 2020), such debates are currently very prominent in public opinion. As a result, we argue that individuals may show some social desirability in responding to questions about victim-blaming and even AMMSA, which were originally designed to measure these beliefs implicitly. Consequently, in this study, the tendency to social desirability has been used as a moderator.

Previous findings in Iran and other countries such as Spain and Italy in which honor beliefs are somehow endorsed demonstrated that the Binding Foundations predict high levels of victim-blaming (Baboli \& KarimiMalekabadi, 2020; Milesi et al., 2020); on the other hand, Individualizing foundations predict lower levels of blaming the rape victims. Endorsement of AMMSA, on the other hand, highly predicts victim-blaming (Milesi et al., 2020).

Given these cases, hypothesizes of this research are as follows:

1. Binding foundations (authority, loyalty, and sanctity) have a positive relationship with victim-blaming, and individualizing foundations (care and harm) have a negative relationship with victim-blaming.

2. Binding foundations (especially authority) predict high levels of victim-blaming, while individualizing foundations (especially care) predict low levels of it.

3. AMMSA correlates positively with victim-blaming and predicts it positively.

4. The tendency to social desirability moderates the relationship between AMMSA and moral foundations with victim-blaming.

\section{Method}

\subsection{Participants}

Participants were a community sample of 216 Iranians ( $62 \%$ female, $M=24.53, S D=4.63)$. Questionnaires were provided online to the participants through social media (for example, Instagram, Telegram, etc.). Most participants stated that they have university-level education (high school Diploma or less, 3\%; bachelor's or bachelor's student 60\%; master's or master's student, 31\%; Ph.D. or Ph.D. Candidate, 5\%). The age range of the participants was 18-47 years.

\subsection{Instruments}

\subsubsection{Victim blaming}

To assess participants' victim-blaming, we used the victim-blaming scenario based on Milesi et al. (2020) study. Since in most rapes the rapist is a familiar person, we used a story in which the characters have a background of acquaintanceship together. Moreover, we tried to change the story somehow; therefore, it complies with Iranian norms and is more understandable for Iranian participants. The items and the questionnaire were translated to Persian and then back-translated to English by a professional English translator. Both English and Persian versions of the questionnaire showed high levels of internal consistency ( $\alpha=0.86$ and $\alpha=0.89$, respectively). 
A short story was provided to participants, and after the reading, they answered six questions with the contents of victim-blaming; all items were rated along a 7 -point scale ranging from $1=$ not at all to $7=$ very much. Higher scores indicated higher levels of victim-blaming rather than perpetrator. The questions were: (1) To what extent should Niloufar be blamed for what happened? / (2) To what extent Niloufar made Nima believe she wants to have sex? / (3) To what extent Niloufar's behavior contributed to what happened? / (4) To what extent could have Niloufar avoid this event? / (5) To what extent Niloufar is like those people who put themselves in dangerous situations? / (6) To what extent Niloofar can be held responsible for the happening? The scenario can be seen below:

Niloufar and Nima met at university and were together for two months. One day, Niloufar invites Nima to her house for a cup of tea. At this point, Niloufar says: "however I had told Nima that I do not want to have a sexual relationship, he hugged me and started kissing me. Finally, I realized I could not resist without being harmed anymore; Nima pushed me and raped me." But Nima says: "although

Niloufar was a little reluctant at first, she never showed any signs of unhappiness; therefore, I didn't realize she wasn't happy with what is happening; also, she didn't show any opposition or resistance during sex."

\subsubsection{Acceptance of Modern Myths about Sexual Aggression (AMMSA)}

The AMMSA scale (Gerger et al., 2007) contains 30 items that evaluate the participants' agreement with modern myths about sexual aggression. It is a self-report scale in which participants choose their level of approval based on a 7-scale ranging from 1= totally disagree to 7 = totally agree (for instance, "Once a man and a woman have started "making out", a woman's misgivings against sex automatically disappear", "Any woman who is careless enough to walk through "dark alleys" at night is partly to be blamed if she is raped."). As there was no reliable measure in Persian, its English version was translated to Persian and then backtranslated to English by a Professional translator. The internal consistency of Persian version was similar to the original version $(\alpha=0.88)$.

\subsubsection{Moral Foundations Questionnaire (MFQ)}

To assess the moral foundations of participants we used the Persian version of the Moral foundation questionnaire scale (Graham et al., 2013; Nejat \& Hatami, 2019). Internal consistency of Persian version for each foundation is Care $\alpha=0.69$, Fairness $\alpha=0.65$, Loyalty $\alpha=0.71$, Authority $\alpha=0.74$, and Sanctity $\alpha=0.84$, which is similar to the original version of the questionnaire.

The Moral foundation questionnaire consists of two subsets of 'relevance' and 'judgment.' Each section includes 15 items. In both sections, participants have to read each item and determine their agreement in a 6-scale ranging. In the relevance section, participants were asked to rate 'how important are each following considerations when deciding whether something is right or wrong?' they had to choose from $1=$ not important at all to 6 = extremely important. (e.g., Care: whether or not someone has suffered emotionally, Fairness: whether or not someone has been treated differently, Loyalty: whether or not someone's action was in the direction of love for his or her country, Authority: whether or not someone has disrespected to the authorities, Sanctity: whether or not someone has violated the limits of purity and decency).

In the judgment section, participant's moral judgment in various circumstances was evaluated; they were asked to specify the range of their agreement with each statement from $1=$ strongly disagree to $6=$ strongly agree. (e.g., Care: "compassion is the essential virtue for those who suffer", Fairness: "When the government makes laws, the first principle must be to ensure that everyone is treated fairly", Loyalty: "I am proud of my country's history", Authority: "respect for authorities have to be taught to children", Sanctity: "people should not do disgusting things, even if no one is harmed"). 


\subsubsection{Social Desirability Scale}

In order to measure participants' social desirability tendencies, the short form of the Social Desirability Scale (Ballard, 1992; Crowne \& Marlowe, 1960) was used. It is a self-report test in which participants have to answer true/false questions, and the total score is based on the sum of true or false responses in each item (e.g., "There have been occasions when I took advantage of someone," "I'm always willing to admit it when I make a mistake"). The Persian version of the scale contains nine questions and its internal consistency has been reported $\alpha=0.75$ and $\alpha=0.87$ (Mohseni \& Mirgol, 2020).

\section{Results}

\subsection{Correlational and Regression Analyses}

Table 1 demonstrates the results of descriptive statistics and correlational coefficients. According to the obtained data, AMMSA has the highest association with blaming the rape victim, which is consistent with the findings of previous studies. Regarding the Moral Foundations, we can see that Binding Foundations (Loyalty, Authority, and Sanctity) have a positive and significant relationship with victim-blaming. Among the Binding Foundations, Authority, Sanctity, and Loyalty have the highest associations with victim-blaming, respectively. These findings are consistent with the assumptions that AMMSA and Binding Foundations have a relationship with conservative socio-political beliefs (Graham et al., 2009; Milesi et al., 2020; Süssenbach \& Bohner, 2011). On the other hand, it can be seen that Individuating Foundations (Care and Fairness) have a weak, negative association with victim-blaming, which is not significant statistically. These findings are not in accordance with previous findings suggesting that Individuating Foundations negatively correlate with victim-blaming.

In order to determine which variables predicted victim-blaming, we ran a hierarchical regression. 5 Moral foundations were included in step 1, and AMMSA was involved in step 2 of the regression. The findings are presented in Table 2. As we can see, in step 1, Authority and Sanctity were the positive predictors, and Fairness was the negative predictor of victim-blaming. In step 2, as predicated, AMMSA was the strongest predictor of the dependent variable. Moreover, Authority, Sanctity, and (marginally) Fairness were still predictors of victim-blaming.

\subsection{Moderator Analyses}

As mentioned before, to determine if Social Desirability moderate participants' answers, this variable was included as a moderator in the analyses. Data was analyzed with Model 1 of PROCESS Macro for SPSS (Hayes, 2017). In each analysis, each variable and sub-variables that were not involved in analyses served as covariates. Results showed that Care significantly interacted with Social Desirability to influence predicting victim-blaming (Table 3). Social Desirability did not influence other variables. Conditional effects showed that when the tendency to Social Desirability was low (M-1 SD), Care did not influence victim-blaming, $B=0.18 \quad(p=0.38)$; however, when the tendency to Social Desirability was high $(M+1 S D)$, Care led to increased blaming of the rape victim (Figure 1).

\subsection{Country Comparisons}

By comparing the hierarchical regression results in our study and Milesi et al. (2020), some differences were obtained (Table 2). As can be seen, in all four countries, victim-blaming was best predicted by AMMSA, but its value was less severe in Iran. Variance described by Moral Foundations in stages 1 and 2 was almost similar in all countries with some levels of culture of honor. There is a difference between countries as to which moral foundations predict victim-blaming. In Germany, for example, Care was important in stage 1; However, its effectiveness was lost after involving AMMSA in stage 2. Fairness in stage 1 was almost similar between Spain, Italy, and Iran, and in stage 2 remained the same except for Italy. Fairness in Italy, Spain, and Iran predicted 
victim-blaming at both stages, but it was more severe in Iran. In general, it can be noted that in Italy, Spain, and Germany, after involving AMMSA in stage 2, described variance by Moral Foundations' decrease, and AMMSA was the strongest predictor of victim-blaming. However, although the influence of other moral foundations diminished after AMMSA was involved in stage 2, Authority and Sanctity remained almost the same in predicting the victim-blaming.

In order to determine if the differences in the regression coefficients of Iran with the other three countries that we assumed to be less honored are significant, this contrast was used: Germany, Italy, and Spain=-2 and Iran=+1. We combined our data with the data obtained from Milesi et al. (2020)'s study for this analysis. This contrast compared Germany, Italy, and Spain (three countries supposed to be less honored) with Iran (a highly honored culture). This contrast was involved in stage 3. The interaction terms of moral foundations with the mentioned contrast were also analyzed in stage 4 (all variables were mean-centered). Results indicated a significant effect of Contrast $\times$ Authority $(B=.14, p=.001)$, which implies that the positive impact of Authority on victim-blaming in Iran is stronger than the other three countries. Moreover, results showed a significant positive effect of Contrast effect $\times$ Sanctity $(B=.09 p=.024)$, which, like the interaction effect of Fairness, indicates a more substantial positive effect of Sanctity on victim-blaming in Iran compared to the other three countries.

\section{Discussion}

Sexual violence is the most severe trauma that a women can experience during her lifetime. Victims of rape are often held responsible and blamed for what happened to them. Research on the causes and roots of victim-blaming has been mostly conducted in WEIRD countries. In order to examine this issue in a traditional, non-weird society, based on (Milesi et al., 2020), we attempted to study the interplay of moral foundations and modern myths about sexual aggression with victim-blaming, with the moderating role of social desirability in the Iranian sample. Making judgments of rape victims is a moral intuition, and we have argued that individuals' judgments of rape victims may be influenced directly or indirectly by different moral foundations. In this study, the moral foundations theory, proposed by (Graham et al., 2013; Haidt, 2012) Was used, which combines individualizing (care and fairness) and binding moral foundations (loyalty, authority, and sanctity). Based on previous research, we hypothesized that individualizing foundations and binding foundations would negatively and positively correlate with victim-blaming, respectively. In addition, we hypothesized that AMMSA would have a positive relationship with victim-blaming and will predict it.

We found that in Iran, both individualizing foundations have non-significant relationships with victimblaming. This finding contradicts the results of previous studies (Milesi et al., 2020; Niemi \& Young, 2016), which indicated a negative relationship between individualizing foundations and victim-blaming. On the other hand, there is a positive relationship between binding moral foundations and victim-blaming. However, in comparison with the other two foundations, this association was lower in Loyalty. Comparing this with the findings obtained from other countries (Milesi et al., 2020), we see that in Iranian culture, Authority (which posits that it is morally wrong to challenge traditional structures, gender roles, and current status quo) and Sanctity (which associates promiscuous sexual activity with the concept of contamination) are more endorsed and individuals place more emphasis on them in their moral judgments related to victim-blaming. Therefore, it can be argued that people who endorse binding foundations (Particularly Authority and Sanctity) will have higher levels of victim-blaming. These findings are consistent with previous studies conducted in countries with a relatively high culture of honor (Spain and Italy). Moreover, unlike other countries, after AMMSA was involved in regression, these two foundations continued to predict victim-blaming in levels very similar to AMMSA (Table 3). 
Our study also found that AMMSA was the strongest predictor of victim-blaming, which is consistent with previous findings in this area (Gerger et al., 2007; Lonsway \& Fitzgerald, 1994; Milesi et al., 2020). In this regard, it is worth mentioning that it was the first time this questionnaire was translated and used to measure this concept. Persian version of AMMSA questionnaire showed high levels of validity (Cronbach's alpha $=.88$ ). In addition, its correlation with conservative socio-political structures (Binding foundations), which are usually associated with the greater acceptance of rape myths, indicates a logical validity.

In this study, assuming that the tendency to social desirability may affect the participant's responses, we involved this variable as moderator. Care foundation has a relationship with empathy with others, and as a result, in people with lower empathy, lower levels of Care may lead to more victim-blaming. Results showed that social desirability has a moderating effect on Care. In individuals with a high tendency to social desirability, Care leads to increased victim-blaming.

Regarding gender differences, we did not find a significant difference between men and women in victimblaming. Our findings are consistent with the results of Baboli and Karimi-Malekabadi (2020) in Iranian samples. This finding in Iranian culture contradicts previous findings in western cultures, which suggested that men's tendency to victim-blaming is higher than women (Grubb \& Turner, 2012; Pinciotti \& Orcutt, 2017). The lack of difference between male and female participants may be due to the established structures about appropriate behaviors for men and women in Iranian society. However, men and women had significant differences in AMMSA, Authority, and Fairness. Men tend to believe more in modern myths about sexual violence, while women emphasize the two foundations of Authority and Fairness.

When comparing the data belonging to Iran and the other three European countries obtained by Milesi et al. (2020), we observed that in Iran, Authority and Sanctity's effect in predicting victim-blaming was more than the other three countries. On the other hand, in line with previous findings, and contrary to the predictions of Harper and Harris (2017), Loyalty could not predict victim-blaming in Iran. Regarding Authority, our findings were consistent with Baboli and Karimi-Malekabadi (2020). Authority has an emphasis on the tendency to maintain the status quo and traditional gender roles of society. More respect for the authorities, which in most traditional societies are men and was the perpetrator in our victim-blaming scenario, predicts more victim-blaming.

Regarding Sanctity, we can point to the high sensitivity of Iranian culture to women's behavior in society. Due to concepts such as "Haya" and "Namoos" in Iranian culture, women's sexual behaviors are usually described through the metaphors of cleanliness and contamination. For example, many honor killings in Iran are carried out under the slogan and mentality of "Cleaning the Namoos." High sensitivity to avoiding contamination may lead to high levels of victim-blaming in this culture. Therefore, if we consider Iran as a culture that is more honored than Spain and Italy, and Spain and Italy as cultures that are more honored than Germany, we can conclude that in countries with a culture of honor, Authority and Sanctity are positive predictors, and Fairness is a negative predictor of victim-blaming.

\subsection{Limitations and Further suggestions}

Our research had some limitations, which we will mention in the following. First, our research data was obtained through social media. Thus, the obtained data may not represent individuals belonging to the lower socio-economic classes of Iranian society, in which victim-blaming and rape myths are much more common. As a result, we suggest that future research use all potential socio-economic categories in Iran, especially the lower classes who may not have access to social networks. Secondly, Iran comprises different ethnicities (for example, Persians, Turks, Arabs, Lurs, etc.), each of which has different attitudes and norms in facing these issues. In another word, the culture of honor in these ethnicities comes in various forms. Therefore, we suggest that future studies examine and compare the differences in Iranian ethnicity in more detail. 
Research on sexual violence and its relationship with different structures in Iran are in its early stages, and not much research literature is available. Our findings contradicted other findings in many ways. Considering our results and other findings, such as (Baboli \& Karimi-Malekabadi, 2020), further research is needed to elucidate the exact connections between moral foundations and victim-blaming, especially in individualizing foundations. In addition, it seems helpful to expand this research using culturally specific foundations and concepts, such as the concept of "Gheirat".

\section{Conclusion}

In this study, we used Moral Foundations as a descriptive framework, assuming that blaming rape victims is a type of moral judgment to which individuals respond intuitively based on their previous experiences and learnings. Our research was conducted in Iran, a highly honored culture. Consistent with those findings in other countries, AMMSA and binding foundations positively correlate with victim-blaming. Two of them (Authority and Sanctity) could predict victim-blaming. On the other hand, we saw that Fairness negatively predicted victim-blaming. This finding is vital for Iranian culture. Training programs designed to address individuals' perceptions of rape victims through the fairness foundation can ultimately reduce victim-blaming in a given society. Given that culture has a significant impact on moral judgments, such researches can encourage victims to report rape experiences and improve the overall circumstances for rape victims through identifying the causes of victim-blaming and designing intervention methods.

\section{Conflict of Interest}

The author(s) declared no conflicts of interest regarding the research, authorship, and/or publication of this article.

\section{Funding}

This research did not receive any specific grant from funding agencies in the public, commercial, or not-forprofit sectors.

\section{References}

Abrams, D., Viki, G. T., Masser, B., \& Bohner, G. (2003). Perceptions of stranger and acquaintance rape: The role of benevolent and hostile sexism in victim blame and rape proclivity. Journal of personality and social psychology, 84(1), 111.

Aghtaie, N. (2011). Breaking the silence: rape law in Iran and controlling women's sexuality. Internatlonal approaches to rape, 121.

Aghtaie, N. (2017). Rape within heterosexual intimate relationships in Iran: legal frameworks, cultural and structural violence. Families, relationships and societies, 6(2), 167-183.

Atari, M., Graham, J., \& Dehghani, M. (2020). Foundations of morality in Iran. Evolution and Human Behavior, 47(5), 367-384.

Atari, M., \& Jamali, R. (2016). Dimensions of women's mate preferences: Validation of a mate preference scale in Iran. Evolutionary Psychology, 14(2), 1474704916651443.

Baboli, M. F., \& Karimi-Malekabadi, F. (2020). Qeirat Values and Victim Blaming in Iran: The Mediating Effect of Culture-Specific Gender Roles.

Ballard, R. (1992). Short forms of the Marlowe-Crowne social desirability scale. Psychological reports, 71(3_suppl), 1155-1160.

Bandura, A. (1986). Social foundations of thought and action. Englewood Cliffs, NJ, 1986(23-28). 
Bastani, H. (2017). Is rape more common in Sweden than in the Middle East? . https://www.bbc.com/persian/iran-features-41709699

Bohner, G., Eyssel, F., Pina, A., Siebler, F., \& Viki, G. T. (2013). Rape myth acceptance: Cognitive, affective and behavioural effects of beliefs that blame the victim and exonerate the perpetrator. In Rape (pp. 4068). Willan.

Bohner, G., Reinhard, M. A., Rutz, S., Sturm, S., Kerschbaum, B., \& Effler, D. (1998). Rape myths as neutralizing cognitions: Evidence for a causal impact of anti-victim attitudes on men's self-reported likelihood of raping. European Journal of Social Psychology, 28(2), 257-268.

Bohner, G., Siebler, F., \& Raaijmakers, Y. (1999). Salience of rape affects self-esteem: Individual versus collective self-aspects. Group Processes \& Intergroup Relations, 2(2), 191-199.

Bohner, G., Siebler, F., \& Schmelcher, J. (2006). Social norms and the likelihood of raping: Perceived rape myth acceptance of others affects men's rape proclivity. Personality and Social Psychology Bulletin, 32(3), 286-297.

Brown, S. L. (2007). Counseling victims of violence: A handbook for helping professionals. Hunter House.

Brownmiller, S. (1975). Against Our Will: Men. Women and Rape, 15, 105.

Burt, M. R. (1980). Cultural myths and supports for rape. Journal of personality and social psychology, 38(2), 217.

Campbell, R. (2008). The psychological impact of rape victims. American psychologist, 63(8), 702.

Campbell, R., Sefl, T., Barnes, H. E., Ahrens, C. E., Wasco, S. M., \& Zaragoza-Diesfeld, Y. (1999). Community services for rape survivors: Enhancing psychological well-being or increasing trauma? Journal of consulting and clinical psychology, 67(6), 847.

Crowne, D. P., \& Marlowe, D. (1960). A new scale of social desirability independent of psychopathology. Journal of consulting psychology, 24(4), 349.

Farajiha, M., \& Azari, H. (2011). Critical approach to criminal protection of victim women of rape in Iran law. Social Welfare Quarterly, 17(40), 287-314.

FIS, F. I. S. (2015). Violence Against Women And Honour-related Violance In Iran. https://migri.fi/documents/5202425/5914056/61597 Suuntausraportti Vakivaltalran finalFINAL kaannosversio EN.pdf/04123eff-529a-457a-aa0d-d5218d046ffe

Frese, B., Moya, M., \& Megías, J. L. (2004). Social perception of rape: How rape myth acceptance modulates the influence of situational factors. Journal of Interpersonal Violence, 19(2), 143-161.

Gerger, H., Kley, H., Bohner, G., \& Siebler, F. (2007). The acceptance of modern myths about sexual aggression scale: Development and validation in German and English. Aggressive Behavior: Official Journal of the International Society for Research on Aggression, 33(5), 422-440.

Glick, P., \& Fiske, S. T. (2001). Ambivalent sexism. In Advances in experimental social psychology (Vol. 33, pp. 115-188). Elsevier.

Graham, J., Haidt, J., Koleva, S., Motyl, M., lyer, R., Wojcik, S. P., \& Ditto, P. H. (2013). Moral foundations theory: The pragmatic validity of moral pluralism. In Advances in experimental social psychology (Vol. 47, pp. 55-130). Elsevier.

Graham, J., Haidt, J., \& Nosek, B. A. (2009). Liberals and conservatives rely on different sets of moral foundations. Journal of personality and social psychology, 96(5), 1029.

Gray, K., Young, L., \& Waytz, A. (2012). Mind perception is the essence of morality. Psychological inquiry, 23(2), 101-124.

Grubb, A., \& Turner, E. (2012). Attribution of blame in rape cases: A review of the impact of rape myth acceptance, gender role conformity and substance use on victim blaming. Aggression and violent behavior, 17(5), 443-452. 
Haidt, J. (2001). The emotional dog and its rational tail: a social intuitionist approach to moral judgment. Psychological review, 108(4), 814.

Haidt, J. (2012). The righteous mind: Why good people are divided by politics and religion. Vintage.

Harper, C. A., \& Harris, A. J. (2017). Applying moral foundations theory to understanding public views of sexual offending. Journal of sexual aggression, 23(2), 111-123.

Hayes, A. F. (2017). Introduction to mediation, moderation, and conditional process analysis: A regression-based approach. Guilford publications.

HOSB. (2009). Home Office Statistical Bulletin 11/09. Crime in England \& Wales, 2008/9: London: Home Office. Jamalzadeh, M. A. (1966). Personality Traits of Iranians. Tehran: Foroughi.

Kar, M. (2015). Rape of young girl in Iran met with muted responses. www. mehrangizkar.net/english/

Kohlberg, L., \& Hersh, R. H. (1977). Moral development: A review of the theory. Theory into practice, 16(2), 5359.

Krahé, B. (1988). Victim and Observer Characteristics as Determinants of Responsibility Attributions to Victims of Rape 1. Journal of Applied Social Psychology, 18(1), 50-58.

Laing, L. (2017). Secondary victimization: Domestic violence survivors navigating the family law system. Violence against women, 23(11), 1314-1335.

Lonsway, K. A., \& Fitzgerald, L. F. (1994). Rape myths. In review. Psychology of women quarterly, 18(2), 133164.

Mason, G. E., Riger, S., \& Foley, L. A. (2004). The impact of past sexual experiences on attributions of responsibility for rape. Journal of Interpersonal Violence, 19(10), 1157-1171.

Megías, J. L., Romero-Sánchez, M., Durán, M., Moya, M., \& Bohner, G. (2011). Spanish validation of the acceptance of modern myths about sexual aggression scale (AMMSA). The Spanish Journal of Psychology, 14(2), 912-925.

Milesi, P., Süssenbach, P., Bohner, G., \& Megías, J. L. (2020). The interplay of modern myths about sexual aggression and moral foundations in the blaming of rape victims. European Journal of Social Psychology, 50(1), 111-123.

Mohseni, S., \& Mirgol, A. (2020). Determining the Role of Islamic Lifestyle, Social Desirability and Self-Efficacy with Happiness and Mental Health in Students. Health Research Journal, 5(3), 137-143.

Nejat, P., Bagherian, F., Shokri, O., \& Hatami, J. (2015). Mental representation of morality: The endorsement pattern of moral foundations among Iranians. 2015 Sixth International Conference of Cognitive Science (ICCS),

Nejat, P., Bagherian, F., Shokri, O., \& Hatami, J. (2016). The pattern of reliance on moral foundations within mental representations of ideal society, and moral and immoral behaviors in an Iranian sample. Advances in Cognitive Science.

Nejat, P., \& Hatami, J. (2019). Psychometric properties of the Persian version of Moral Foundations Questionnaire in three Iranian samples. Social Cognition, 8(1), 107-124.

Niemi, L., \& Young, L. (2016). When and why we see victims as responsible: The impact of ideology on attitudes toward victims. Personality and Social Psychology Bulletin, 42(9), 1227-1242.

Nisar, S. (2021). Ambivalent Sexism towards Women and Acceptance of Rape Myths among University Students. Saudi J. Humanities Soc Sci, 6(2), 90-95.

Onsi, A. (2017). SECONDARY VICTIMIZATION OF RAPE VICTIMS IN IRAN. In: Malmö högskola/Hälsa och samhälle.

Page, T. E., \& Pina, A. (2018). Moral disengagement and self-reported harassment proclivity in men: the mediating effects of moral judgment and emotions. Journal of sexual aggression, 24(2), 157-180. 
Payne, D. L., Lonsway, K. A., \& Fitzgerald, L. F. (1999). Rape myth acceptance: Exploration of its structure and its measurement using thelllinois rape myth acceptance scale. Journal of Research in Personality, 33(1), 27-68.

Pinciotti, C., \& Orcutt, H. (2017). Understanding Gender Differences in Rape Victim Blaming: The Power of Social Influence and Just World Beliefs. Journal of Interpersonal Violence, 886260517725736886260517725736.

Razavi, P., Shaban-Azad, H., \& Srivastava, S. (2020). Gheirat as a complex emotional reaction to relational boundary violations. https://doi.org/https://doi.org/10.31234/osf.io/8ev23.

Sanchez-Ruiz, M.-J., El Ahmad, P., Karam, M., \& Saliba, M. A. (2021). Rape myth acceptance in Lebanon: The role of sexual assault experience/familiarity, sexism, honor beliefs, and the Dark Triad. Personality and Individual Differences, 170, 110403.

Schein, C., Goranson, A., \& Gray, K. (2015). Schein, C., Goranson, A., \& Gray, K.(2015). The uncensored truth about morality. The Psychologist, 28 (12), 982-985. Psychologist, 28(12), 982-985.

Sepehri Far, T. (2020, 09/11/2020). Iran is having its \#MeToo moment. Aljazeera. https://www.aljazeera.com/indepth/opinion/iran-metoo-moment-200908130623823.html

Shahali, S., Mohammadi, E., Lamyian, M., Kashanian, M., Eslami, M., \& Montazeri, A. (2016). Barriers to healthcare provision for victims of sexual assault: a grounded theory study. Iranian Red Crescent Medical Journal, 18(3).

Süssenbach, P., \& Bohner, G. (2011). Acceptance of sexual aggression myths in a representative sample of German residents. Aggressive Behavior, 37(4), 374-385.

Swim, J. K., Aikin, K. J., Hall, W. S., \& Hunter, B. A. (1995). Sexism and racism: Old-fashioned and modern prejudices. Journal of personality and social psychology, 68(2), 199.

Tabatabai, M. H. (1996). al-Mizan fi Tafsir al-Qur'an. Qom: Islamic Publications Society of Seminary Teachers of Qom, 2.

UN. (2018). Human development report. http://hdr.undp.org/en/2018-update

Vecina, M. L., \& Piñuela, R. (2017). Relationships between ambivalent sexism and the five moral foundations in domestic violence: is it a matter of fairness and authority? The Journal of psychology, 157(3), 334344.

Watts, A. L., Bowes, S. M., Latzman, R. D., \& Lilienfeld, S. O. (2017). Psychopathic traits predict harsh attitudes toward rape victims among undergraduates. Personality and Individual Differences, 106, 1-5.

WHO. (2021). Violence against women prevalence estimates, 2018: global, regional and national prevalence estimates for intimate partner violence against women and global and regional prevalence estimates for non-partner sexual violence against women.

Wilson, C., Goodwin, S., \& Beck, K. (2002). Rape attitude and behaviour and their relationship to moral development. Psychiatry, Psychology and Law, 9(1), 85-95.

Winkel, F. W., \& Koppelaar, L. (1991). Rape victims' style of self-presentation and secondary victimization by the environment: An experiment. Journal of Interpersonal Violence, 6(1), 29-40. 
Table 1. Descriptive Statistics and Correlational Coefficients of Variables across Iranian Samples

\section{Correlations}

\begin{tabular}{|c|c|c|c|c|c|c|c|c|c|}
\hline & M & SD & Victim Blaming & AMMSA & Care & Fairness & Loyalty & Authority & Sanctity \\
\hline Victim Blaming & 4.20 & 1.46 & 1 & & & & & & \\
\hline AMMSA & 3.43 & .83 & $.56^{\star \star}$ & 1 & & & & & \\
\hline Care & 4.80 & .57 & -.01 & -.09 & 1 & & & & \\
\hline Fairness & 5.03 & .56 & -.05 & -.12 & $.52^{* *}$ & 1 & & & \\
\hline Loyalty & 4.15 & .84 & $.28^{* *}$ & $.18^{* *}$ & $.37^{* *}$ & $.37^{* *}$ & 1 & & \\
\hline Authority & 3.65 & .94 & $.56^{* *}$ & $.39^{* *}$ & $.18^{* *}$ & $.22^{* \star}$ & $.60^{* *}$ & 1 & \\
\hline Sanctity & 4.13 & .94 & $.50^{* *}$ & $.29^{* *}$ & $.37^{* *}$ & $.33^{* *}$ & $.54^{* *}$ & $.66^{* *}$ & 1 \\
\hline
\end{tabular}


Table 2. Hierarchical Regressions of Victim Blaming on Moral Foundations and AMMSA in Iran, Spain, Italy, Germany. Data of Spain, Italy, and Germany are retrieved from Milesi et al. (2020).

\begin{tabular}{|c|c|c|c|c|c|c|c|c|}
\hline & \multicolumn{2}{|c|}{ Iran } & \multicolumn{2}{|c|}{$\begin{array}{l}\text { Spain } \\
\text { St: }\end{array}$} & \multicolumn{2}{|c|}{ Italy } & \multicolumn{2}{|c|}{ Germany } \\
\hline & Step 1 & Step 2 & Step 1 & Step 2 & Step 1 & Step 2 & Step 1 & Step 2 \\
\hline \multicolumn{9}{|l|}{ Step 1} \\
\hline Care & -.09 & -.05 & $-.21^{*}$ & $-.13^{\dagger}$ & -.08 & -.04 & $-.20^{*}$ & -.10 \\
\hline Fairness & $-.19^{\star \star}$ & $-.13^{*}$ & $-.27^{* \star}$ & $-.14^{+}$ & $-.24^{* *}$ & -.06 & -.03 & .03 \\
\hline Loyalty & -.07 & -.06 & .01 & $-.17^{*}$ & .10 & .02 & .14 & .05 \\
\hline Authority & $.43^{\star \star \star}$ & $.31^{\star \star \star}$ & $.21^{*}$ & $.13^{+}$ & .13 & -.03 & $.18^{+}$ & -.01 \\
\hline Sanctity & $.35^{\star \star \star}$ & $.30^{* \star \star}$ & $.19^{*}$ & $.14^{*}$ & $.24^{*}$ & $.15^{+}$ & $.14^{+}$ & .02 \\
\hline \multicolumn{9}{|l|}{ Step 2} \\
\hline AMMSA & & $.34^{\star \star \star}$ & & $.55^{* \star \star}$ & & $.60^{\star \star \star}$ & & $.61^{* * *}$ \\
\hline$\Delta R 2$ & .41 & .09 & .23 & .22 & .22 & .26 & .17 & .25 \\
\hline Total $R 2$ & & .50 & & .45 & & .47 & & .42 \\
\hline \multicolumn{9}{|c|}{$\begin{array}{l}\text { Note: Standardized regression coefficients }(\beta) \text { are displayed. } \\
{ }^{+} p<0.10 \\
{ }^{*} p<0.05 \\
{ }^{* *} p<0.01 \\
{ }^{* *} p<0.001 .\end{array}$} \\
\hline
\end{tabular}


Table 3. Moderation Analyses of Social Desirability with AMMSA and Moral Foundations on Victim Blaming

\begin{tabular}{ccc}
\hline & Coeff $(\beta)$ & Conditional effects \\
\hline AMMSA & 0.584 & - \\
Care & $-0.1606^{\star}$ & $-1.8432(-1 \mathrm{SD}) b=.1794$ \\
Fairness & -0.1253 & $1.834(+1 S \mathrm{SD}) \mathrm{b}=0.42^{\star}$ \\
Loyalty & -0.507 & - \\
Authority & 0.349 & - \\
Sanctity & -0.0257 & - \\
\hline
\end{tabular}

Note: Standardized regression coefficients ( $\beta$ ) are displayed.

${ }^{*} \mathrm{p}<0.05$.

Figure 1. The Moderator Effect of Social Desirbility on the relationship of Care and VB

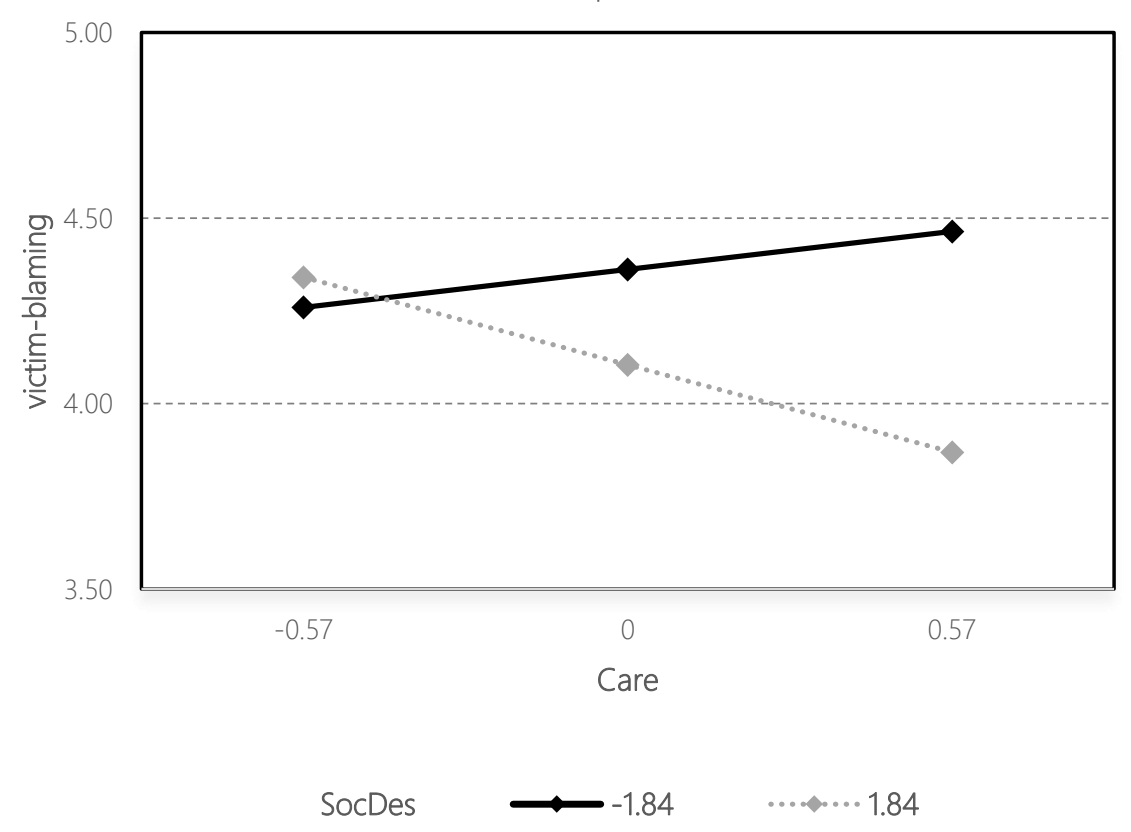

